\title{
Preparation and Study of a Composite Flocculant for Papermaking Wastewater Treatment
}

\author{
Defang Zeng ${ }^{1,2}$, Dan Hü ${ }^{1,2}$, Jie Cheng ${ }^{1,2}$ \\ ${ }^{1}$ School of Resource and Environmental Engineering, Wuhan University of Technology, Wuhan, China; ${ }^{2}$ Hubei Key Laboratory of \\ Mineral Resource Processing and Environment, Wuhan, China. \\ E-mail: 516777198@qq.com
}

Received September $16^{\text {th }}, 2011$; revised October $23^{\text {rd }}, 2011$; accepted November $25^{\text {th }}, 2011$.

\begin{abstract}
A high flocculation performance composite flocculant was prepared with sodium alginate, polyaluminium ferric chloride and cationic polyacrylamide. And the composite flocculant was used in papermaking wastewater treatment. Results indicated that it achieve the best flocculation performance when the raw material mass ratio was 2:1:1, the dosage of the composite flocculant was $20 \mathrm{mg} / \mathrm{L}$, and the removal efficiency of COD and turbidity with this composite flocculant reached $89.6 \%$ and $99.2 \%$, respectively.
\end{abstract}

Keywords: Sodium Alginate, Polyaluminium Ferric Chloride, Cationic Polyacrylamide, Flocculation

\section{Introduction}

Papermaking wastewater contains lignin, cellulose, difficult degradation substances and many tiny colloidal materials [1-3]. And flocculation is widely used to papermaking wastewater pretreatment or advanced treatment [4]. Flocculants are the materials, which are used in fast solid-liquid separations. They act on a molecular level on the surfaces of the particles to reduce repulsive forces and increase attractive forces [5].

Sodium alginate flocculant is widely used in medicine, food, printing, dyeing, papermaking and other industries as its gelling ability, stabilizing properties, and high viscosity in aqueous solutions [6-8]. Sodium alginate is a polysaccharide carbohydrate which is a linear polymer consisting of (1-4)-poly- $\beta$-D-mannuronic acid and (1-4)$\alpha$-L-guluronic acid [9-11]. Sodium alginate can be extracted from the kelp seaweeds and other algae [12]. Sodium alginate is a flocculation reinforcing agent in papermaking wastewater treatment and it is acted as a framework material in flocculation. It will accelerate the forming of flocculation particles and shorten the time of flocculation.

As an inorganic polymer flocculant, polyaluminium ferric chloride is widely used in industrial wastewater because of the bigger flocs, more rapid settling and wide subject range of $\mathrm{pH}$ compared with aluminum sulfate and polyaluminium chloride [13]. And cationic polyacrylamide as a flocculant aid, it could reduce the dosage of flocculants, increase the flocculation rate and improve the stability of flocs in wastewater treatment [14]. Aguilar et al. used polyacrylamide as flocculant aid to improve the process of coagulation-flocculation [15].

On the basis of the advantages of sodium alginate, polyaluminium ferric chloride and cationic polyacrylamide, we tried to prepare a composite flocculant consisting of sodium alginate, polyaluminium ferric chloride and cationic polyacrylamide to treat papermaking wastewater. The main objective of this study was to evaluate the flocculation performance of the composite flocculant.

\section{Materials and Methods}

\subsection{Materials}

Sodium alginate (SA) was procured from Chemical Reagent Factory (Shanghai, China). Polyaluminium ferric chloride (PAFC) was purchased from Chemical Co., LTD (Shenyang, China). Cationic Polyacrylamide (CPAM) was obtained from Silver Rings Chemical Co., LTD (Guangzhou, China). All chemicals were of analytical grade.

\subsection{Preparation of the Composite Flocculant}

SA, PAFC and CPAM were added to the distilled water until dissolution to make a stock solution, respectively. The stock solution of SA, PAFC and CPAM was mixed using a magnetic stirrer (Model 78-1, Jintan splendor equipment manufacture Co., LTD, Jiangsu, China), adjusting $\mathrm{pH}$, stirring and settling for some period of time 
to prepare the composite flocculant.

\subsection{Flocculation Experiment}

Wastewater samples from the wastewater before air flotation phase with $1208 \mathrm{mg} / \mathrm{L}$ of COD, $415 \mathrm{NTU}$ of turbidity value, 7.1 of $\mathrm{pH}$ and $30^{\circ} \mathrm{C}$ of water temperature was supplied by a Paper Mill located at Hubei province in China.

In each experiment, once the composite flocculant was added, the wastewater was stirred at a certain velocity for a few minutes on a six-port combined mixer (Model S2-1, Scientific Apparatus Company, Shengzhen, China), kept the wastewater settling for a while, the upper fluid was used to measure COD and turbidity in the treated water samples.

COD was measured with a COD digestion device (Model 5B-1C, Lian Hua Environmental Protection Science and Technology Co., LTD, Lanzhou, China). Turbidity was measured with a turbidity meter (Model XZ- 1B, Lei Gu Apparatus Co., LTD., Shanghai, China). All experiments were conducted at least in triplicate.

\section{Results and Discussion}

\subsection{The Preparation Conditions of the Composite Flocculant}

The orthogonal experimental was conducted to confirm the optimum conditions of the composite flocculant. And the mass ratio of the raw material, $\mathrm{pH}$ and reaction time were chosen as the factors. Table 1 was the orthogonal layout of the composite flocculant. Table 2 was the results of the orthogonal experimental. $\mathrm{k}_{1}, \mathrm{k}_{2}, \mathrm{k}_{3}$ were the mean removal efficiencies of COD each factor under three levels. And $\mathrm{k}_{\mathrm{I}}, \mathrm{k}_{\Pi}, \mathrm{k}_{\amalg}$ were the mean removal efficiencies of turbidity each factor under three levels. As shown in Table 2, the optimum formula was $\mathrm{A}_{2} \mathrm{~B}_{3} \mathrm{C}_{2}$ on removing $\mathrm{COD}$ and turbidity. On removing $\mathrm{COD}$, the influence of the materials' mass ratio was much more than $\mathrm{pH}$ and reaction time, and the influence of reaction time was more than $\mathrm{pH}$. On removing turbidity, the materials' mass ratio was the most influence, the next was reaction time and the last was $\mathrm{pH}$. When SA:PAFC:CPAM was $2: 1: 1$, the best flocculation performance was achieved.

\subsection{Effect of Dosage of the Composite Flocculant}

To determine the effect on COD and turbidity removal

Table 1. Orthogonal layout of the composite flocculant.

\begin{tabular}{cccc}
\hline Factors & A(SA:PAFC:CPAM) & $\mathrm{B}(\mathrm{pH})$ & $\mathrm{C}($ Reaction time/h) \\
\hline Level 1 & $1: 1: 1$ & 5.5 & 1 \\
Level 2 & $2: 1: 1$ & 6.5 & 1.5 \\
Level 3 & $2: 2: 1$ & 7.5 & 2 \\
\hline
\end{tabular}

Table 2. Orthogonal layout of the composite flocculant and its analysis.

\begin{tabular}{cccccc}
\hline Factors & A & B & C & $\begin{array}{c}\text { Removal rate } \\
\text { of COD (\%) }\end{array}$ & $\begin{array}{c}\text { Removal rate of } \\
\text { turbidity (\%) }\end{array}$ \\
\hline 1 & 1 & 1 & 1 & 75.6 & 86.2 \\
2 & 2 & 2 & 2 & 80.5 & 91.8 \\
3 & 3 & 3 & 3 & 71.2 & 83.7 \\
4 & 1 & 2 & 3 & 74.8 & 83.9 \\
5 & 2 & 3 & 1 & 79.4 & 91.0 \\
6 & 3 & 1 & 2 & 70.7 & 85.4 \\
7 & 1 & 3 & 2 & 73.9 & 85.9 \\
8 & 2 & 1 & 3 & 74.4 & 85.1 \\
9 & 3 & 2 & 1 & 64.3 & 80.0 \\
$\mathrm{k}_{1}$ & 74.767 & 73.567 & 73.100 & & \\
$\mathrm{k}_{2}$ & 78.100 & 73.200 & 75.033 & & \\
$\mathrm{k}_{3}$ & 72.100 & 74.833 & 73.467 & & \\
$\mathrm{R}$ & 6.000 & 1.533 & 1.933 & & \\
$\mathrm{k}_{\mathrm{I}}$ & 85.333 & 85.567 & 85.733 & & \\
$\mathrm{k}_{\Pi}$ & 89.300 & 85.233 & 87.700 & & \\
$\mathrm{k}_{\amalg}$ & 83.033 & 86.867 & 84.233 & & \\
$\mathrm{R}$ & 6.267 & 1.634 & 3.467 & & \\
\hline & & & & & \\
\hline
\end{tabular}

using composite flocculant, a series of tests were conducted to determine the optimal dosage of composite flocculant. Six kinds dosage of the composite flocculant were prepared. And the optimal one was determined. The results indicated that the optimal dosage was sample 4, as shown in Table 3. And the optimal dosage of the composite flocculant was $20 \mathrm{mg} / \mathrm{L}$. The efficiency in the removal of COD and turbidity were enhanced with the increased dosage of composite flocculant. And the removal efficiencies of COD and turbidity reached the highest level when treated by sample 4 flocculant formula. However, with the continuously increased dosage of composite flocculant, the effect on reducing the concentrations of COD and turbidity was gradually decreasing. It was because that the particles would be encompassed by excess dosage of composite flocculant, losing the chance to combine with other particles and reaching another stable situation. It made the particles difficult to aggregation and reduced the flocculation efficiency. So, the optimal dosage was

Table 3. Effect of dosage on flocculation effect.

\begin{tabular}{cccc}
\hline Sample & $\begin{array}{c}\text { Dosage of the composite } \\
\text { flocculant (mg/L) }\end{array}$ & $\begin{array}{c}\text { Removal rate of } \\
\text { COD }(\%)\end{array}$ & $\begin{array}{c}\text { Removal rate of } \\
\text { turbidity }(\%)\end{array}$ \\
\hline 1 & 5 & 75.6 & 88.6 \\
2 & 10 & 79.1 & 91.5 \\
3 & 15 & 81.9 & 93.3 \\
4 & 20 & 83.5 & 95.8 \\
5 & 25 & 76.7 & 95.1 \\
6 & 30 & 76.2 & 93.7 \\
\hline
\end{tabular}


sample 4 composite flocculant, and the optimal removal efficiency of COD and turbidity were $83.5 \%$ and $95.8 \%$, respectively.

\subsection{Effect of pH Value}

A series of tests were conducted to study the flocculation effectiveness of composite flocculant under different $\mathrm{pH}$ $(3.08,5.18,7.18,8.10,9.08,10.10)$. Wastewater sample was treated under the six different $\mathrm{pH}$ values. The experimental results in Table 4 showed that the highest removal rate of COD and turbidity at $\mathrm{pH} 7-8$. The explanation for this as follows: Colloidal substances were usually negatively charged in papermaking wastewater, while CPAM contained acylamino and it had great cationic degree and strong positive electricity, so that it had a good charge neutralization ability and it could adsorb particles for compressing double-charge-layer to made particles destabilize. Besides, the methyl of acylamino was hydrophobic. It would reach toward the surrounding in wastewater sample; increased the interfacial tension of solid-liquid, the repulsive force and the contact angle of water; thus improved the effect of flocculation. But it would reduce the treatment effect when $\mathrm{pH}$ value was too high. The alkaline environment was prone to cause rapid hydrolysis of aluminum ions in flocculation and the charge neutralization ability would be reduced [16].

\subsection{Effect of Stirring Speed}

A series of tests were conducted to study the flocculation effectiveness of composite flocculant under different stirring speed. The experimental results in Table 5 showed that the removal efficiency of COD and turbidity reached

Table 4. Influence of pH on flocculation effect.

\begin{tabular}{ccc}
\hline $\mathrm{pH}$ & Removal rate of COD $(\%)$ & Removal rate of turbidity (\%) \\
\hline 3.08 & 76.4 & 81.2 \\
5.18 & 79.6 & 92.4 \\
7.18 & 83.7 & 94.9 \\
8.10 & 85.8 & 97.0 \\
9.08 & 81.7 & 94.7 \\
10.10 & 74.4 & 81.3 \\
\hline
\end{tabular}

Table 5. Influence of rapid stirring speed on flocculation effect.

\begin{tabular}{ccc}
\hline $\begin{array}{c}\text { Rapid stirring } \\
\text { speed (r/min) }\end{array}$ & $\begin{array}{c}\text { Removal rate } \\
\text { of COD }(\%)\end{array}$ & $\begin{array}{c}\text { Removal rate } \\
\text { of turbidity }(\%)\end{array}$ \\
\hline 140 & 78.2 & 90.1 \\
160 & 81.4 & 92.6 \\
180 & 84.2 & 95.4 \\
200 & 87.1 & 97.3 \\
220 & 83.8 & 94.4 \\
240 & 81.6 & 91.8 \\
\hline
\end{tabular}

$87.1 \%$ and $97.3 \%$, respectively, at the rapid stirring speed of $200 \mathrm{r} / \mathrm{min}$. And Table 6 showed that the removal efficiency of COD and turbidity reached $87.8 \%$ and $97.5 \%$, respectively, at the slow stirring speed of $40 \mathrm{r} / \mathrm{min}$. It could be attributed to the effect of mixture and reaction stages of the flocculation process [17]. At the mixture stage, rapid stirring speed was required to make the composite flocculant diffuse into the wastewater rapidly and evenly. It created good conditions for the hydrolytic polymerization and made colloid destabilization and aggregation. At the reaction stage, slow stirring speed was required to make flocculation particles into large flocs with good settalbility. But the stirring speed should not be too fast as it would break down the flocs and affected the effect of flocculation. So, the stirring speed played an important role in flocculation.

\subsection{Effect of Stirring Time}

A series of tests were conducted to study the flocculation effectiveness of composite flocculant under various stirring time. The experimental results in Table 7 showed that the removal efficiency of COD and turbidity reached $88.4 \%$ and $98.2 \%$, respectively, at the rapid stirring time of $2.5 \mathrm{~min}$. And Table 8 showed that the removal efficiency of COD and turbidity reached $89.1 \%$ and $98.9 \%$, respectively, at the slow stirring time of $9 \mathrm{~min}$. The explanation for this was two-folded: At the mixture stage, it only needed few minutes to make the composite flocculant diffuse into wastewater and got good flocculation effect. At the reaction stage, it needed a little longer to make the

Table 6. Influence of slow stirring speed on flocculation effect.

\begin{tabular}{ccc}
\hline $\begin{array}{c}\text { Slow stirring } \\
\text { speed }(\mathrm{r} / \mathrm{min})\end{array}$ & $\begin{array}{c}\text { Removal rate } \\
\text { of COD }(\%)\end{array}$ & $\begin{array}{c}\text { Removal rate } \\
\text { of turbidity }(\%)\end{array}$ \\
\hline 20 & 79.0 & 91.3 \\
30 & 83.4 & 95.4 \\
40 & 87.8 & 97.5 \\
50 & 84.3 & 96.2 \\
60 & 82.5 & 93.8 \\
70 & 80.2 & 92.5 \\
\hline
\end{tabular}

Table 7. Influence of rapid stirring time on flocculation effect.

\begin{tabular}{ccc}
\hline $\begin{array}{c}\text { Rapid stirring } \\
\text { time }(\text { min) }\end{array}$ & $\begin{array}{c}\text { Removal rate } \\
\text { of COD }(\%)\end{array}$ & $\begin{array}{c}\text { Removal rate } \\
\text { of turbidity }(\%)\end{array}$ \\
\hline 0.5 & 79.1 & 91.7 \\
1.0 & 80.9 & 93.0 \\
1.5 & 83.6 & 95.2 \\
2.0 & 86.4 & 96.3 \\
2.5 & 88.4 & 98.2 \\
3.0 & 85.8 & 96.6 \\
\hline
\end{tabular}


Table 8. Influence of slow stirring time on flocculation effect.

\begin{tabular}{ccc}
\hline $\begin{array}{c}\text { Slow stirring } \\
\text { time (min) }\end{array}$ & $\begin{array}{c}\text { Removal rate } \\
\text { of COD }(\%)\end{array}$ & $\begin{array}{c}\text { Removal rate } \\
\text { of turbidity }(\%)\end{array}$ \\
\hline 6 & 82.5 & 92.9 \\
7 & 84.6 & 95.6 \\
8 & 86.3 & 97.0 \\
9 & 89.1 & 98.9 \\
10 & 87.8 & 97.2 \\
11 & 83.4 & 94.3 \\
\hline
\end{tabular}

flocculation particles into big one and it would sediment rapidly so as to improved flocculation effect. The second reason was the effect of sodium alginate. As a polymeric flocculant, sodium alginate mixed in wastewater only need few minutes and it would make sense rapidly.

\subsection{Effect of Settling Time}

Settling time had a direct influence on the effect of flocculation. A series of tests were conducted to study the flocculation effectiveness of composite flocculant under various settling time $(10,15,20,25,30,35 \mathrm{~min})$. The removal rate of COD and turbidity reached $89.6 \%$ and $99.2 \%$, respectively, at the settling time of $30 \mathrm{~min}$ as shown in Table 9. Sediment stage followed after the flocculation process. The removal rate of COD and turbidity would very low if the settling time was too short. Some of small flocs and suspended matter would not reach the bottom of the beakers so as to the low removal efficiency of COD and turbidity. The removal rate of COD and turbidity would increase with the increasing of settling time. But it would stay the same when the settling time reached the optimal one.

\subsection{The Mechanism of Flocculation}

Sodium alginate was an anionic polyelectrolyte and it was a high polymer material with carboxyl groups. It had the structure of three-dimensional. Sodium alginate was a flocculation reinforcing agent in papermaking wastewater treatment and it was acted as a framework material in flocculation.

Polyaluminium ferric chloride was an inorganic macromolecule flocculant. It combined the advantages of aluminum salt and ferric salt flocculant. Polyaluminium ferric chloride made the colloid destabilization and aggregation [18]. Its own positive charge would neutralize negative charge of the colloid to make the colloid into flocs and sediment so as to remove pollutants.

Cationic polyacrylamide was an organic macromolecule flocculant. Its polymer long chain which was adsorbing on the surface of the particles would adsorb the other particles. That was, cationic polyacrylamide linked many particles together and made them into flocs [19,20]. Besides, its positive charge would neutralize negative charge of the co-
Table 9. Influence of settling time on flocculation effect.

\begin{tabular}{ccc}
\hline $\begin{array}{c}\text { Settling time } \\
(\mathrm{min})\end{array}$ & $\begin{array}{c}\text { Removal rate } \\
\text { of COD }(\%)\end{array}$ & $\begin{array}{c}\text { Removal rate } \\
\text { of turbidity }(\%)\end{array}$ \\
\hline 10 & 85.9 & 94.8 \\
15 & 86.4 & 96.3 \\
20 & 87.0 & 97.2 \\
25 & 88.1 & 98.3 \\
30 & 89.6 & 99.2 \\
35 & 89.6 & 99.2 \\
\hline
\end{tabular}

lloid to make the colloid into flocs and sediment so as to remove pollutants.

With the adding of sodium alginate in wastewater, it was good at adsorbing the colloid at the synergistic effect of materials which closed to carboxyl groups. And the positive charge of polyaluminium ferric chloride and cationic polyacrylamide neutralized negative charge of sodium alginate to avoid decreasing the removal rate of COD and turbidity. Besides, positive charge's mutual superposition of polyaluminium ferric chloride and cationic polyacrylamide could improve the ability of charge neutrality.

With the force of sodium alginate, polyaluminium ferric chloride and cationic polyacrylamide, the composite flocculant made a good flocculation performance on removing COD and turbidity in papermaking wastewater.

\section{Conclusions}

A composite flocculant was prepared for treating papermaking wastewater and its effect of the flocculation was studied. And the conclusions as follows:

- The composite flocculant consisting of sodium alginate, polyaluminium ferric chloride and cationic polyacrylamide and the optimal dosage of the composite flocculant was $20 \mathrm{mg} / \mathrm{L}$;

- The optimal treatment conditions were that $\mathrm{pH}$ value was adjusted to 7 - 8; rapid stirring speed and slow stirring speed were $200 \mathrm{r} / \mathrm{min}$ and $40 \mathrm{r} / \mathrm{min}$, respectively; rapid stirring time and slow stirring time were $2.5 \mathrm{~min}$ and $9 \mathrm{~min}$, respectively; and settling time was $30 \mathrm{~min}$.

- The highest removal rate of COD and turbidity with the composite flocculant reached $89.6 \%$ and $99.2 \%$, respectively.

\section{Acknowledgements}

This project was supported through ministry of science and technology in China of small medium enterprise technology innovation foundation and department of science and technology in Hubei province, China of science and technology research foundation, which we thank together in this. 


\section{REFERENCES}

[1] H. L.Wang, G. S. Liu, P. Li and F. Pan, "The Effect of Bioaugmentation on the Performance of Sequencing Batch Reactor and Sludge Characteristics in the Treatment Process of Papermaking Wastewater," Bioprocess and Biosystems Engineering, Vol. 29, No. 5-6, 2006, pp. 283289. doi:10.1007/s00449-006-0077-9

[2] Y. Matsushita, A. Iwatsuki and S. Yasuda, "Application of Cationic Polymer Prepared from Sulfuric Acid Lignin as a Retention Aid for Usual Rosin Sizes to Neutral Papermaking," The Japan Wood Research Society, Vol. 50, No. 6, 2004, pp. 540-544. doi:10.1007/s10086-003-0602-2

[3] V. C. Srivastava, I. D. Mall and I. M. Mishra, "Treatment of Pulp and Paper Mill Wastewater with Polyaluminium Chloride and Bagasse Fly Ash," Colloids and Surfaces A: Physicochemical and Engineering Aspects, Vol. 260, No. 1-3, 2005, pp. 17-28. doi:10.1016/j.colsurfa.2005.02.027

[4] X. W. Yang, Y. D. Shen and P. Z. Li, “ Intrinsic Viscosity, Surface Activity, and Flocculation of Cationic Polyacrylamide Modified with Fluorinated Acrylate," Polymer Bulletin, Vol. 65, No. 2, 2010, pp. 111-122. doi:10.1007/s00289-009-0186-0

[5] B. R. Sharma, N. C. Dhuldhoya and U. C. Merchant, "Flocculants-An Ecofriendly Approach," Journal of Polymers and the Environment, Vol. 14, No. 2, 2006, pp. 195202. doi:10.1007/s10924-006-0011-X

[6] T. A. Becker, D. R. Kipke and T. Brandon, "Calcium Alginate Gel: A Biocompatible and Mechanically Stable Polymer for Endovascular Embolization," Journal of Biomedical Materials Research, Vol. 54, No. 1, 2001, pp. 7686. doi:10.1002/1097-4636(200101)

[7] S. Martins, B. Sarmento, E. B. Souto and D. C. Ferreira, "Insulin-Loaded Alginate Microspheres for Oral DeliveryEffect of Polysaccharide Reinforcement on Physicochemical Properties and Release Profile," Carbohydrate Polymers, Vol. 69, No. 4, 2007, pp. 725-731. doi:10.1016/j.carbpol.2007.02.012

[8] X. J. Huang, Y. Xiao and M. D. Lang, "Micelles/SodiumAlginate Composite Gel Beads: A New Matrix for Oral Drug Delivery of Indomethacin," Carbohydrate Polymers, Vol. 87, No. 1, 2012, pp. 790-798. doi:10.1016/j.carbpol.2011.08.067

[9] L. H. Fan, X. R. Pan, Y. Zhou, L. Y. Chen, W. G. Xie, Z. H. Long and H. Zheng, "Preparation and Characterization of Crosslinked Carboxymethyl Chitosan-Oxidized Sodium Alginate Hydrogels," Journal of Applied Polymer Science, Vol. 122, 2011, pp. 2331-2337. doi:10.1002/app.34041

[10] S. R. V. Tomme, G. Storm and W. E. Hennink, "In Situ
Gelling Hydrogels for Pharmaceutical and Biomedical Applications," International Journal of Pharmaceutics, Vol. 355, No. 1, 2008, pp. 1-18. doi:10.1016/j.ijpharm.2008.01.057

[11] H. X. Liu, C. Y. Wang, Q. X. Gao, X. X. Liu and Z. Tong, "Fabrication of novel Core-Shell Hybrid Alginate Hydrogel Beads," International Journal of Pharmaceutics, Vol. 351, No. 1, 2008, pp. 104-112. doi:10.1016/j.ijpharm.2007.09.019

[12] A. Shilpa, S. S. Agrawal and A. R. Ray, "Controlled Delivery of Drugs from Alginate Matrix," Journal of Macromolecular Science Part C-Polymer Review, Vol. 43, No. 2, 2003, pp. 187-221. doi:10.1081/MC-120020160

[13] Y. H. Li, X. L. Li and W. H. Li, "Study on Polyaluminium Ferric Chloride for Treating Papermaking Wastewater and Regeneration," North Environment, China, No. 4, 2002, pp. 67-69.

[14] S. S. Wong, T. T. Teng, A. L. Ahmad, A. Zuhairi and G. Najafpour, "Treatment of Pulp and Paper Mill Wastewater by Polyacrylamide in Polymer Induced Flocculation," Journal of Hazardous Materials B, Vol. 135, No. 1-3, 2006, pp. 378-388. doi:10.1016/j.jhazmat.2005.11.076

[15] M. I. Aguilar, J. Sáez, M. Lloréns, A. Soler, J. F. Ortuño, V. Meseguer and A. Fuentes, "Improvement of Coagulation-Flocculation Process Using Anionic Polyacrylamide as Coagulant Aid," Chemosphere, Vol. 58, No. 1, 2005, pp. 47-56. doi:10.1016/j.chemosphere.2004.09.008

[16] N. Carlos, M. S. Luis and F. Elena, "Polyacrylamide Induced Floccluation of a Cement Ssuspension," Chemical Engineering Science, Vol. 61, No. 8, 2006, pp. 2522-2532. doi:10.1016/j.ces.2005.11.013

[17] J. Nan, W. P. He, J. J. Song and G. B. Li, "Characteristics of the Dynamic Distribution of Suspended Particles in the Flocculation Process," Journal of Zhejiang University Science A, Vol. 10, No. 9, 2009, pp. 1350-1358. doi:10.1631/jzus.A0820652

[18] M. A. A. Razali, Z. Ahmad, M. S. B. Ahmad and A. Ariffin, "Treatment of Pulp and Paper Mill Wastewater with Various Molecular Weight of PolyDADMAC Induced Flocculation," Chemical Engineering Journal, Vol. 166, No. 2, 2011, pp. 529-535. doi:10.1016/j.ces.2010.11.011

[19] P. Peng and G. Garnier, "Effect of Cationic Polyacrylamide Adsorption Kinetics and Lonic Strength on Precipitated Calcium Carbonate Flocculation," Langmuir, Vol. 26, No. 22, 2010, pp. 16949-16957. doi:10.1021/la103410j

[20] Z. Liang and Y. X. Wang, "Pretreatment of Diosgenin Wastewater Using Polyferric Sulfate and Cationic Polyacrylamide," Journal of Earth Science, Vol. 21, No. 3, 2010, pp. 340-360. doi:10.1007/s12583-010-0097-x 